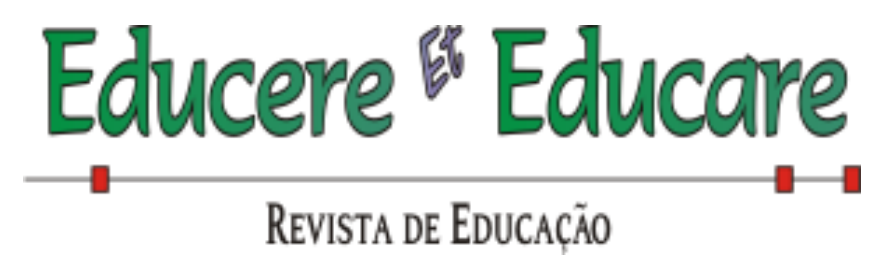

Programa de Pós-Graduação em Educação - Universidade Estadual do Oeste do Paraná

\title{
RELATO DE EXPERIÊNCIAS ENTRE BRASIL E ESPANHA: O ATENDIMENTO EDUCACIONAL ESPECIALIZADO DE CRIANÇAS COM ALTAS HABILIDADES/SUPERDOTAÇÃO A PARTIR DA LITERATURA CIENTÍFICA
}

\author{
Me. Carla Sant Ana de Oliveira \\ Universidade Federal do Paraná \\ Dra. Carla Luciane Blum Vestena
}

Universidade Estadual do Centro-Oeste do Paraná

RESUMO: O presente artigo visa analisar as práticas de atendimento educacional especializado para crianças com Altas Habilidades/Superdotação no contexto do Brasil e da Espanha e exposta na literatura científica internacional. A experiência da Espanha foi escolhida para essa análise por ser uma referência internacional no que tange a qualidade de atendimento às necessidades específicas dos superdotados. Para a realização da pesquisa que embasou este artigo encontramos na análise bibliográfica de documentos oficiais, artigos científicos e obras da literatura científica os subsidios necessários para suscitar nossas reflexões. Como resultado, encontramos dados que indicam que o Brasil tem conquistado importantes avanços, principalmente via NAAH/S e Salas de Recursos Multifuncionais que empregam o enriquecimento curricular e a flexibilização educacional como práticas de atendimento, o que converge com a experiência espanhola. Todavia, ainda nos faltam alguns aspectos para alcançar êxito, como os processos de avaliação escolar, a formação de professores e o acompanhamento de equipes de orientação como existe na Espanha.

PALAVRAS-CHAVE: Equipe de Orientação; Enriquecimento Curricular; Flexibilização.

\section{REPORT OF EXPERIENCES BETWEEN BRAZIL AND SPAIN: THE SPECIALIZED EDUCATIONAL SERVICE FOR GIFTED CHILDREN BASED ON SCIENTIFIC LITERATURE}

\begin{abstract}
The objective of this paper is to analize specialized educational service practices to gifted children in Brazil and Spain and the international scientific literature. Spanish experience was chosen to this analysis because it is an international reference regarding quality of services for gifted children' specific needs. This paper was based on the subsidies that we found to our reflections in bibliographic analysis of official documents, scientifics papers and other scientific works. Results are
\end{abstract}

we found the information that Brazil has had important progresses specialy from NAAH/S and Multifuncional Resource Classes where there is curricular enrichment and educational flexibility as service practices, what is in accord with Spanish experience. However, there are not some aspects to be successful as scholar evaluation processes, specifics formation for teachers and the help from an orientation team as there is in Spain.

KEYWORDS: Orientation Team; Curricular Enrichment; Flexibility. 


\section{Educere "Educare \\ Revista de EduCAČ̃̃o}

Programa de Pós-Graduação em Educação - Universidade Estadual do Oeste do Paraná

\section{INTRODUÇÃO}

Na busca por compreender o que é Altas Habilidades/Superdotação, esse trabalho foi realizado a partir da análise da experiência realizada na Espanha, cuja Lei Geral da Educação que trata do atendimento educacional especializado data de 1970, desde então há uma grande preocupação no país em abordar, identificar, avaliar e principalmente atender as crianças com AH/SD desde a Educação Infantil, Educação Primária e ESO , conforme nos apresentam Galvéz et. al. (2000); Prieto (1989), Ferrando et. al. (2007); Comes et. al. (2008), Sternberg et. al. (2000).

Em seguida, nossa investigação passou a analisar o Atendimento Educacional no Brasil, com objetivo de refletir sobre as formas de atendimento, os avanços e retrocessos existentes no país, a partir do modelo efetivado na Espanha. Padrão este que se destaca na experiência e serve de exemplo à pesquisadores e educadores que visam a qualidade educacional para crianças com Altas Habilidades/Superdotação.

Dentro desse âmbito, verificamos alguns avanços importantes no contexto brasileiro que indicam que estamos no caminho certo para a realização de um trabalho de referência para o contexto internacional. Isso deve-se ao fato de que importantes pesquisadores brasileiros tais como Pérez e Freitas (2014), Almeida, Fleith e Oliveira (2013), Alencar, Bruno-Faria e Fleith (2010), Piske, Bahia, Machado e Stoltz (2014), Virgolim e Konkiewitz (2014), Machado e Vestena (2016) entre outros têm se dedicado exaustivamente ao tema e realizado uma luta pelos direitos das pessoas com Altas Habilidades/Superdotação, como bem demonstra o Conselho Brasileiro de Altas Habilidades/Superdotação.

Para a realização desta pesquisa, efetuamos uma revisão de literatura a partir de artigos encontrados no banco de dados do Scielo e livros cujas discussões cingissem o atendimento educacional especializado para estudantes com Altas Habilidades/ Superdotacão nos contextos do Brasil e da Espanha. Para Revista Educere Et Educare, Vol. 13, N. 29, set./out. 2018. Ahead of Print. 


\section{Educere "Educare \\ Revista de EduCAČ̃̃o}

Programa de Pós-Graduação em Educação - Universidade Estadual do Oeste do Paraná

fundamentar a discussão deste artigo, elegeu-se os pesquisadores com trabalhos publicados entre 2000 e 2017 e cujas pesquisas são referenciadas por outros pesquisadores, nestes dois contextos.

\section{Contribuições para o atendimento educacional especializado de crianças com AH/SD.}

Os pesquisadores espanhóis indicam que não basta detectar os sujeitos portadores de Altas habilidades, mas é necessário estabelecer avaliações psicopedagógicas constantes e específicas para cada sujeito.

Na perspectiva de Gálvez e Gonzáles (2000) essa avaliação tende a valorizar as intervenções quanto a sua efetividade e também por fornecer o parâmetro da maturação emocional, cognitiva e física dos sujeitos com AH/SD. Portanto, a avaliação nesse sentido deve ser minuciosa, aplicada por uma equipe com formação específica em psicologia e pedagogia. Todavia, durante as práticas pedagógicas se torna inviável promover as avaliações, pois essas podem se tornar exaustivas para as crianças.

Nos espaços escolares deve-se realizar pequenas e simples análises descritivas baseadas nas reações dos sujeitos à prática pedagógica e ao ambiente educacional, observando quais são as decisões que o sujeito toma frente às circunstancias que ele vivencia, dessa forma é possivel (re)organizar as práticas de atendimento educacional de modo específico para cada sujeito, é necessário conhecer a quem se endereça o atendimento educacional para que ele seja realmente eficiente na sua especialização

Para realizar o atendimento das crianças superdotadas o Ministério da Educação e Cultura (1995), criou equipes de orientação que tinham como principal objetivo elaborar formação para professores, atendimento à família, identificação, avaliação e plano de atendimento educacional especializado às crianças com Altas Habilidades/Superdotação desde a Educação Infantil. 


\section{Educere "Educare \\ ReVISTA DE EduCACÃ̃o}

Programa de Pós-Graduação em Educação - Universidade Estadual do Oeste do Paraná

Nesse sentido, o Brasil tem que realizar um minucioso processo de identificação em todo país, processo esse que por ora, está sendo realizado pontualmente sob a influência do Conselho Brasileiro de Altas Habilidades/Superdotação (CONBRASD) e dos Núcleos de Atividades para Altas Habilidades/Superdotação (NAAHS). Mas, ainda falta a avaliação periódica das crianças com Altas Habilidades/Superdotação como ocorre na Espanha.

Além disso, Prieto (1989) lembra que é necessário que haja investimentos na formação docente e na organização de Equipes de Orientação, que trabalhariam como um apoio psicopedagógico para os professores que atendem alunos com Altas Habilidades/Superdotação. Esse grupo trabalharia no sentido de planejar a flexibilização do currículo escolar, organizar monitorias dos alunos com AH/SD para auxiliar colegas que tenham dificuldades de aprendizagem e, assim desenvolver suas habilidades socioafetivas por meio da interação mediada.

Outra possibilidade de intervenção da Equipe de Orientação, junto aos professores seria a busca por tutorias de diversos profissionais que auxiliariam as crianças com Altas Habilidades/Superdotação a realizarem projetos de pesquisa e de extensão em atividades extraescolares, tais como projetos de eletrônica, produções artísticas, captação de recursos e instrumentos para realização de atividades científicas e de extensão. E também fica responsável pela elaboração de documentos que possam contribuir para a atuação e formação dos professores no processo de identificação e na elaboração de práticas pedagógicas adaptadas como aponta Esparza (2017) é indispensável dar respostas educativas adequadas aos estudantes com AH/SD.

Para Gálvez e Gonzáles (2000, p.11) a intervenção educacional precisa considerar o contexto educacional em que as crianças superdotadas se encontram e, em seguida, elaborar projetos para enriquecer o Atendimento Educacional Especializado, considerando as características afetivas, cognitivas e físicas dos sujeitos, esses projetos devem ser modelos abertos, interativos e autorregulados. 


\section{Educere "Educare \\ Revista de EduCAČ̃̃o}

Programa de Pós-Graduação em Educação - Universidade Estadual do Oeste do Paraná

Deve-se considerar que a criança com Altas habilidades/Superdotação é sucessivel a ter problemas afetivos e sociais durante o processo de aprendizagem, especialmente, quando não há respeito a sua potencialidade, ou mesmo as dificuldades que apresentam. Por isso, é comum verificar a existência de sentimentos como frustração e desmotivação o que pode resultar no fracasso escolar.

Uma forma eficiente de impedir esse fracasso escolar é evitar atividades repetitivas, procedimento eficiente para que a desmotivação dessas crianças não ocorra, é promover meios de socialização, uma vez que as crianças com Altas Habilidades/Superdotação só desenvolvem seu potencial cognitivo, criativo, afetivo e social quando o ambiente lhes proporciona superar suas dificuldades e realizar atividades desafiadoras.

De acordo com Comes, Díaz, Luque, Moliner (2008) a avaliação psicopedagógica precede ao planejamento das intervenções que serão realizadas com as crianças com Altas Habilidades/Superdotação, durante o planejamento cabe ao professor favorecer o desenvolvimento das habilidades sociais, motoras e cognitivas dessas crianças e entender que novas e diferentes habilidades podem surgir com a maturação delas.

Os autores chamam a atenção para o fato de que com o decorrer do desenvolvimento infantil e com os estímulos que as crianças com AH/SD recebem elas podem potencializar diferentes habilidades, por exemplo, se a criança inicialmente é diagnosticada com Altas Habilidades na área da linguagem com o decorrer do tempo ela pode apresentar Altas Habilidades na área tátil-cinestésica, ou artística, o que exigirá do professor uma mudança no modo de atendimento, pois quanto mais áreas forem potencializadas, maiores devem ser os desafios apresentados a essas crianças, para que elas possam obter êxito no seu processo educacional e, desse modo, não se tornem mais um no tenebroso número de crianças que sofrem com o fracasso escolar. 


\section{Educere Educare \\ Revista de EduCAČ̃̃o}

Programa de Pós-Graduação em Educação - Universidade Estadual do Oeste do Paraná

Esparza et. al. (2017, p. 51) defendem que para que a aprendizagem se efetive durante o atendimento educacional especializado é importante distinguir o conhecimento inicial do estudante e a partir destes questioná-los para gerar curiosidade, após essa fase orienta para uma fase de exploração (pesquisa propriamente dita), nessa etapa o estudante pode realizar experiências, reconduzir o conhecimento prévio e cabe ao professor, ou tutor guiá-lo na explicação dos resultados e na expansão de cada descoberta.

Em razão disso, não basta apenas reorganizar o ambiente escolar, formar professores, mas é necessário que a família também seja acompanhada e esse também é um trabalho que deve ser efetuado pela Equipe de Orientação.

A cooperação da família, escola e equipe de orientação é fundamental para que haja a compreensão da maturação biopsicossocial da criança com Altas Habilidades/Superdotação e, ainda mais para delinear como cada sujeito efetiva sua aprendizagem e faz o planejamento para solucionar problemas educacionais e sociais, pois esclarece as motivações e frustrações que as abordagens educativas estão despertando nas crianças, pois só assim pode-se garantir o sucesso da aprendizagem e seus diferentes ritmos, a perseverança com a tarefa que é uma característica forte das crianças com $\mathrm{AH} / \mathrm{SD}$ desde que elas não enfrentem grandes frustrações com tarefas repetitivas.

\subsection{Metodologias de atendimento às crianças com Altas Habilidades/Superdotação no contexto espanhol}

No que tange ao AEE de crianças com Altas Habilidades/Superdotação em escolas da rede regular de ensino da Espanha, a adaptação curricular só pode ser concretizada após a identificação específica para cada caso.

Essa adaptação pode ser realizada mediante a aceleração, ou enriquecimento do currículo escolar com a ampliação de uma ou várias áreas, o que também prevê que haja atividades de aprofundamento, flexibilização da carga 


\section{Educere Educare \\ Revista de EduCAČ̃̃o}

Programa de Pós-Graduação em Educação - Universidade Estadual do Oeste do Paraná

horária para respeitar o ritmo de aprendizagem de cada criança, variações metodológicas com recursos humanos e materiais que possam facilitar a aprendizagem e que permitam o trabalho autônomo da criança, todas estas ações pedagógicas precisam da supervisão do professor e da Equipe de Orientação.

Nesse sentido, o enriquecimento torna-se a forma de atendimento mais adequada, uma vez que beneficiaria toda a classe escolar e não apenas as crianças com Altas Habilidades/Superdotação. Aliás, essa metodologia de trabalho auxiliaria a criança na maturação afetiva por meio de trocas interindividuais com crianças da mesma faixa etária. E lhes proporcionaria atividades variadas com finalidade de colocar os alunos em contato com temas novos e interessantes.

Sobre isso, Comes, Díaz, Luque, Moliner (2008, p.121) indicam que o enriquecimento deve possibilitar o trabalho autônomo, estimular a criatividade, flexibilidade nas atividades, eliminação de conteúdos que o estudante já domina, alargar a profundidade dos conteúdos abordados.

Essa forma de atendimento exige a introdução de conteúdos diferentes daqueles que o grupo desenvolve, esses conteúdos devem estar relacionados com seus temas de interesse das crianças. É importante modificar os temas dos projetos de acordo com as avaliações periódicas, que podem ser realizadas mediante observação da equipe de orientação, aplicação de testes e debates.

Com base nos estudos desenvolvidos pelos pesquisadores espanhóis as atividades desenvolvidas devem contemplar diferentes recursos e métodos, tais como o uso de filmes, revistas científicas diversificadas, educação musical, artes cênicas, visitas à museus e exposições, conhecimentos do meio ambiente e de diferentes culturas por meio de excursões e pesquisas, atividades físicas, demonstrações científicas, uso de laboratórios, intervenções sociais, interações com o meio acadêmico.

Nesse sentido, Ferrandíz, Rojo, Ferrando (2007, p.3) dizem que a flexibilização, por sua vez, garante uma aprendizagem ativa, por meio da 


\section{Educere Educare \\ Revista de EduCAČ̃̃o}

Programa de Pós-Graduação em Educação - Universidade Estadual do Oeste do Paraná

adaptação dos conteúdos e métodos ao potencial cognitivo das crianças. Os autores defendem a exploração de diferentes ambientes relacionados a vida acadêmica e profissionalizante. E que o trabalho cooperativo propicia a maturação emocional das crianças com AH/SD e favorece a criação de vínculos afetivos, desenvolvimento de habilidades como reciprocidade e alteridade entre crianças superdotadas e crianças com dificuldade de aprendizagem.

De acordo com Machado (2013, p.8), as respostas educacionais devem acontecer no ambiente escolar através de estratégias educacionais e metodológicas que atendam o desenvolvimento cognitivo, emocional e a realidade social da criança.

Freitas e Pérez (2012) defendem que é extremamente importante que o professor compreenda que para a criança com Altas Habilidades/Superdotação o trabalho individual é fundamental, pois possibilita uma aprendizagem autônoma, serve de base para comprovar interesses específicos desses alunos com uma série de conhecimentos que podem não estar necessariamente vinculadas ao currículo escolar, mas que são importantes para a vida da criança.

Segundo as autoras, a aprendizagem individual desperta motivação para as crianças com $\mathrm{AH} / \mathrm{SD}$, pois faz com que elas se responsabilizem por seu desempenho com pesquisas extraclasse, que podem designar critérios de produção científica, para tanto deve-se ter presente a figura do professor especialista ou de um tutor, para auxiliar o aluno na aprendizagem de conteúdos que extraordinariamente ultrapassem os limites da escola.

FERRANDO (2007, p.5) diz que é preciso remover barreira para o exercício da criatividade e que o professor deve estimular um ambiente em que a educação ofereça-lhes um conjunto de experiências complementares ao que prevê o currículo escolar e a legislação vigente e que são projetadas de acordo com o desenvolvimento cognoscitivo de cada criança respeitando sua alta capacidade de raciocínio e seu nível de maturação biológica e afetiva. 


\section{Educere Educare \\ ReVISTA DE EduCACÃo}

Programa de Pós-Graduação em Educação - Universidade Estadual do Oeste do Paraná

De acordo com Ferrando (2007) o enriquecimento curricular exige a obtenção de recursos materiais e profissionais de diversas áreas (de acordo com a necessidade educacional de cada criança) que realizem constante orientação aos trabalhos e projetos desenvolvidos pelas crianças. A formulação desses trabalhos demanda qualidade na elaboração técnica, aprofundamento científico, uso da criatividade (inovação), desafio para o raciocinio lógico-matemático e, finalmente a contribuição social.

$\mathrm{O}$ autor defende que é imperativo que o professor coloque a criança com Altas Habilidades/Superdotação em situações de conflito, nas quais elas sejam instigadas a refletirem e se reorganizarem frente aos seus projetos, por isso a indicação da maiêutica como forma de levá-los para um nível de desenvolvimento maior. Essa tática auxilia-os inclusive a não cansarem de seus projetos rapidamente, pois sempre lhes surgirá um novo desafio que serve de estimulo à inteligência delas.

Podemos observar essas práticas no projeto de Seijo, Martínez, López e López (2016, p. 97), que avaliou o impacto de um programa de formação docente sobre a aprendizagem cooperativa e atenção a diversidade mostram a necessidade de investir em formação inicial e continuada para que haja aprendizagem positiva em relação a diversidade de alunos com altas habilidades/superdotação. Contudo, mais uma vez, deve-se preconizar alguns cuidados antes de estabelecer os métodos de Atendimento Educacional Especializado, seja no que se refere ao enriquecimento curricular, ou a flexibilização do ensino.

[...] o atendimento educacional se caracterizará por um processo de inclusão inversa, uma vez matriculados na escola, os alunos com altas habilidades/Superdotação serão alvo de inclusão somente quando encaminhados para a realização de atividades de enriquecimento curricular fora do ambiente de sala de aula regular. Seja em interface com os Núcleos de Atividades de Altas Habilidades/Superdotação (NAAH/S), com as instituições de ensino superior ou com institutos que promovam a pesquisa, as artes e os esportes [...] (DELOU, 2014, p.414).

Sem dúvida, antes de introduzir qualquer metodologia para garantir a aprendizagem é conveniente definir rigorosamente quais são os sujeitos da ação, 


\section{Educere Educare \\ Revista de EduCAČ̃̃o}

Programa de Pós-Graduação em Educação - Universidade Estadual do Oeste do Paraná

como eles podem se beneficiar com essa proposta de ensino, quais os recursos materiais necessários para desenvolver a proposta, quem são os possiveis parceiros que podem contribuir com ela.

O planejamento educacional pode ser em forma de pequenas lições, ou pequenos seminários, demonstrações científicas e tecnológicas, ou ainda mostras de arte. Assim, as crianças aprendem com responsabilidade e exploram uma de suas principais características: o compromisso com a tarefa, por exemplo, podese ter disponível em sala de aula uma pequena biblioteca, com livros de literatura, técnicos, filosóficos, dicionários e científicos para que a criança quando se sentir incomodada por algo que the cause dúvida ela possa ter próximo alguns instrumentos que lhe proporcionarão fazer suas inferências e assim, diminuir a ansiedade.

É muito interessante oportunizar materiais multimídias para que essas crianças de tempos em tempos possam expor suas atividades, seus descobrimentos inclusive sobre os conteúdos escolares, no que eles avançaram para além do que o restante da turma, isso pode até mesmo servir de incentivo para os demais colegas.

A natureza da intervenção precisa ser projetada especificamente para crianças com altas habilidades/Superdotação, já que deve ir além das necessidades imediatas apresentadas por cada um. Em cada momento da aprendizagem a criança necessita ter a sua disposição um conjunto de questionamentos que os ajudem avançar no nível de conhecimentos que vai construindo, além disso, cada momento pedagógico deve estar interligado a momentos passados e a possibilidades futuras.

Pietro (1989) já dizia que para ensinar a criança com Altas habilidades/Superdotação deve prevalecer a interação interindividual (professoraluno/aluno-aluno/aluno-professor), de modo que elas podem se beneficiar dos conhecimentos que construíram no decorrer do processo, elaborando inúmeros 


\section{Educere "Educare \\ Revista de EduCAČ̃̃o}

Programa de Pós-Graduação em Educação - Universidade Estadual do Oeste do Paraná

questionamentos e reflexões sobre suas conquistas. Além disso, a criança poderá observar possiveis falhas no processo, e encontrar diferentes soluções para as lacunas que ficam na aprendizagem, aprendem igualmente descartar informações desnecessárias e se ater apenas ao que realmente é relevante durante o desenvolvimento do projeto.

O estudo realizado por Seijo, Rumayor e Sánches (2016, p.96) em turmas do terceiro ano entre 2013 e 2015 em um centro público de Educação Infantil e Escola Primária de uma comunidade em Madrid na Espanha, buscou compreender o impacto de um programa de aprendizagem cooperativa em situações reais de aula, observou o rendimento emocional e afetivo dos estudantes com $\mathrm{AH} / \mathrm{SD}$, constatou que as habilidades sociais variam de acordo com a relação interpessoal que desenvolvem com os professores principalmente em relação ao questionamento constante destes alunos em relação a aprendizagem.

2.2 Identificar para atender as necessidades educacionais das crianças com Altas Habilidades/Superdotação: uma questão para pesquisadores brasileiros

Com a promulgação da Lei 5692/71 ocorreu a criação do Departamento de Educação Especial, que passou a estudar formas de implementar o atendimento educacional especializado para crianças com Altas Habilidades/Superdotação.

O atendimento educacional para alunos superdotados foi definido, em 1971, na forma de modalidades: enriquecimento curricular e aceleração de estudos, ou as duas modalidades conjugadas. Acrescentou-se a estas a monitoria, programa criado pelo economista Claudio Moura Castro, quando Diretor Geral da Capes, na década de 70 (DELOU, 2012, p.131).

Nos anos 90 que iniciaram as primeiras ações concretas via formação docente. Com a Declaração de Salamanca e por influência do Banco Mundial houve uma reestruturação na Educação Especial, mesmo sem consenso sobre o termo de superdotação, essa passa a ser alvo de discussões, acompanhada pela configuração de Atendimento Educacional Especializado, uma das primeiras Revista Educere Et Educare, Vol. 13, N. 29, set./out. 2018. Ahead of Print. 


\section{Educere "Educare \\ Revista de EduCAČ̃̃o}

Programa de Pós-Graduação em Educação - Universidade Estadual do Oeste do Paraná

medidas tomadas nesse sentido foi a reorganização da Sala de Recursos Multifuncional para atender tanto as crianças com deficiências, transtornos globais do desenvolvimento e com Altas Habilidades/Superdotação.

O período dos anos 2000 foi primordial para a identificação e processos de atendimento especializado no Brasil, já que foi nesse momento que os pesquisadores da área conquistaram maiores avanços, inclusive na produção de documentos oficiais, mas principalmente por causa da organização do Núcleo de Atividades para Altas Habilidades/Superdotação (NAAH/S) em 2006.

$\mathrm{O} \mathrm{NAAH} / \mathrm{S}$ tem se constituído um espaço de pesquisa e desenvolvimento de estratégias de identificação de diferentes habilidades, bem como de promoção de projetos de enriquecimento educacional especializado. Porém, a melhor forma de atender com coerência as crianças com altas habilidades/superdotação é promover um ambiente no qual elas se sintam estimuladas a produzir conhecimento, por meio da pesquisa e de projetos de extensão.

Freitas e Nicoloso (2002) explicam que as crianças superdotadas são altamente criativas e precisam expor seu potencial ao máximo e, nesse contexto, cabe a escola permitir que a criança tenha momentos de criar estratégias para produção de conhecimentos, resolução de problemas e de produção artística.

É importante salientar que criatividade não está somente ligada a uma produção artística, mas sugere dimensões mais amplas, conforme definição do próprio Renzulli (1994), uma aptidão construtiva, originalidade de pensamento, habilidade para deixar de lado as convenções e um dom para idealizar projetos efetivos e originais (FREITAS, NICOLOSO, 2002, p.2).

A originalidade de pensamento, o comportamento flexivel e o alto envolvimento com a tarefa fazem com que o superdotado avance rapidamente no seu processo de construção e de aprimoramento de conhecimentos, por isso a Sala de Recursos Multifuncional tipo I, juntamente com o NAAH/S são 


\section{Educere "Educare \\ Revista de EduCAČ̃̃o}

Programa de Pós-Graduação em Educação - Universidade Estadual do Oeste do Paraná

indispensáveis para dar sustentação a aprendizagem da criança com Altas Habilidades/Superdotação.

Pereira e Guimarães (2007) demonstram que a maior dificuldade que os professores apresentam é justamente de serem flexiveis e adequarem o currículo escolar para atenderem as crianças superdotadas. Observa-se que há ainda muitas carências na formação docente para atuar com crianças com AH/SD, sobre isso Pérez e Freitas (2014) demonstram que os cursos de especialização em AEE oferecidos pela SEESP/MEC (BRASIL, 2010) na modalidade a distância ainda enfatizam as deficiências, mas não apresentam opções de cursos e materiais sobre o AEE para pessoas com AH/SD.

Como consequência deste cenário, percebe-se que professores fazem a associação equivocada entre $\mathrm{AH} / \mathrm{SD}$ e o desempenho escolar extraordinário, à criatividade, à precocidade, ou à genialidade, o que provoca muita confusão na identificação e banaliza o conceito teórico que deve ser definido, esclarecido e explicitado nos documentos educacionais.

[...] A forte vinculação da aprendizagem à infraestrutura material (materiais, equipamentos e mobiliários; bibliotecas, laboratórios, ateliers e materiais escritos "que estimulem a criatividade"), como recurso facilitador do acesso ao currículo e a ausência de indicação de estratégias pedagógicas para mediar esse acesso apontam para a ideia de que esse estudante se autoeduca, que já sabe tudo e apenas precisa de recursos materiais e ambientes facilitadores (PÉREZ, FREITAS, 2014, p. 635).

Ribeiro e Vestena (2017), desenvolveram um programa de formação continuada com educadores infantis, após identificiarem a falta de políticas públicas municipais para inclusão de crianças superdotadas em Guarapuava-PR, os professores que fizeram a formação foram coparticipantes das investigações realizadas no contexto dos centros municipais de Educação Infantil de Guarapuava, durante este programa as autoras lembram que foi possivel a reverção de lacunas metodológicas para atender aos interesses dessas crianças, bem como nos relatos dos educadores percebemos que a formação continuada foi momento de reflexão sobre a educação inclusiva para criança com indicativos de 


\section{Educere "Educare \\ Revista de EduCAČ̃̃o}

Programa de Pós-Graduação em Educação - Universidade Estadual do Oeste do Paraná

$\mathrm{AH} / \mathrm{SD}$ e com isso elaboraram práticas pedagógicas que respeitam e oportunizam diversas situações de aprendizagem e desenvolvimento da criança superdotada.

Outra pesquisa que também trabalhou com formação continuada para professores que atuam com crianças com indicativos de AH/SD foi o projeto de Machado e Vestena (2017), que identificaram 11 crianças após a validação do instrumento de identificação de sujeitos com indicativos de Altas Habilidades/Superdotação em um total de 130 estudantes que participaram desta etapa da pesquisa e que estavam regularmente matriculados nos primeiros anos do Ensino Fundamental das escolas públicas do município de Guarapuava$\mathrm{PR}$, e que demonstram a falta de conhecimento dos professores sobre as características do superdotado e de políticas que estabeleçam o atendimento educacional especializado para esse público.

Almeida, Lobo, Almeida, Rocha e Piske (2017, p. 29) lembram que as necessidades educacionais das crianças superdotadas na maioria das vezes não são acompanhadas de maneira adequada nos contextos escolares, segundo esses autores há ainda muito o que avançar no AEE do superdotado e isso inicia no processo de identificação e caracterização das capacidades intelectuais e potencialidades e só em consequência destes conhecimentos criar programas educacionais especiais.

Muitas instituições educacionais têm se pautado no modelo de enriquecimento desenvolvido por Renzulli (1997, 2004), no qual o estudioso desenvolveu três modelos de atividades:

I. Atividades exploratórias gerais, na qual o aluno entra em contato com os primeiros conhecimentos que podem lhes servir de base.

II. Definir os métodos de pesquisa, aprender a buscar informação em fontes científicas, compreender as normas para produção científica, essa etapa envolve a organização geral de uma pesquisa, serve como estímulo para criança superdotada explorar seu potencial de criação. 


\section{Educere "Educare \\ ReVISTA DE EduCAČ̃̃o}

Programa de Pós-Graduação em Educação - Universidade Estadual do Oeste do Paraná

III. Essas atividades serão aquelas em que a criança pode experimentar a pesquisa, levantar novos dados, criar novas estratégias para solucionar um problema prático e trazer resultados com suas pesquisas que podem beneficiar toda a turma ou, mesmo uma comunidade.

Outra forma de atendimento educacional para as crianças com Altas Habilidades/Superdotação seria o Programa de Aceleração Escolar que embora seja polêmico, pode trazer resultados benéficos se for bem analisado e for feito mediante acompanhamento da criança, da escola e da família por psicólogos por um período de no mínimo dois anos, todavia isso não está disposto no artigo 59 da LDB 9394/96.

O programa de aceleração deve ocorrer mediante acompanhamento da criança e da família para verificar o desenvolvimento socioemocional e cognitivo das crianças superdotadas para garantir o sucesso do programa e não causar prejuizo emocional para as crianças, até porque depois de feita a aceleração não pode-se voltar atrás.

Sendo assim, a criança precisa ter a maturidade e o compromisso de estudar sozinho e superar os conteúdos aos quais não teve acesso previamente e que servem de base aos novos conhecimentos, como prevê a organização curricular educacional brasileira.

A qualidade de vida para criança no ambiente escolar se relaciona diretamente com a forma como o Atendimento Educacional Especializado está organizado, permitindo-lhe criar um autoconceito positivo, explorar as possibilidades de aprendizagem, aprimorarem suas habilidades cognitivas, desenvolverem suas capacidades socioemocionais, enfim vivenciarem desafios, romperem barreiras e explorarem seu potencial criativo.

Por isso, o modelo de atendimento de Renzulli vai de encontro com o que prevê o Plano Nacional de Educação na Meta 4, que visa garantir "o atendimento educacional especializado, preferencialmente na rede regular de ensino, com a 


\section{Educere "Educare \\ Revista de EduCAČ̃̃o}

Programa de Pós-Graduação em Educação - Universidade Estadual do Oeste do Paraná

garantia de sistema educacional inclusivo, de salas de recursos multifuncionais, classes, escolas ou serviços especializados, públicos ou conveniados". Com estratégias como a identificação e atendimento precoce de crianças com Altas Habilidades/Superdotação já na Educação Infantil, formação continuada para o $\mathrm{AEE}$, estimulação de pesquisas via centros multidisciplinares de apoio, pesquisa e assessoria articulando universidade, instituições comunitárias, instituições privadas e escola, assegurar o acesso a recursos didáticos e tecnológicos, pesquisas interdisciplinar.

\section{CONSIDERAÇÕES FINAIS}

Verificamos que há algumas aproximações entre a concepção de Atendimento realizada no Brasil e a experiência da Espanha. É possivel constatar que a Espanha caminha a passos largos a frente do Brasil, uma vez que a política educacional espanhola parece ter uma continuidade e estar funcionando de modo quase que linear em todo o país. Ambos os países sofrem forte influência dos mesmos pesquisadores Guilford, Gardner, Sternberg e Renzulli, na proposta de identificação e atendimento dos superdotados.

Enquanto, no Brasil ainda está se discutindo qual o melhor termo para identificar crianças com alto potencial, na Espanha já se discute claramente êxitos e necessidades no atendimento dessas crianças, ainda fala-se muito em desenvolvimento da inteligência emocional.

Há ainda no Brasil, pouco conhecimento acerca da identidade das crianças superdotadas, principalmente por parte dos educadores brasileiros que ainda compreendem o termo com muitos mitos e equívocos. Existem, diversas discussões sobre as formas de identificação e quase nenhuma discussão sobre avaliação educacional, como verificamos em todos os trabalhos espanhóis, como 


\section{Educere "Educare \\ Revista de EduCAČ̃̃o}

Programa de Pós-Graduação em Educação - Universidade Estadual do Oeste do Paraná

elaborar avaliações que abarquem o pensamento divergente das crianças superdotadas.

Na Espanha não se fala em NAAH/S, mas sim em centros de atendimentos. Verificou-se que é muito forte a questão da monitoria e tutoria da criança superdotada auxiliando os colegas e sendo auxiliada por técnicos e por acadêmicos em projetos individuais e coletivos. No Brasil, observamos a falta de vínculos do ambiente escolar com pessoas da sociedade civil, empresas ou, mesmo universidades.

Ambos os países defendem a questão da flexibilidade curricular, a importância do enriquecimento curricular, entretanto, no Brasil ainda há poucos relatos de como isso ocorre, enquanto na Espanha Estudiosos como Prieto, Gálvez, Gómes já demonstram em seus trabalhos esses relatos, nos quais também apresentam a necessidade de realização de testes de identificação serem reaplicados de tempos em tempos para verificar quais habilidades cognitivas, sociais e motoras as crianças podem apresentar.

Outra coincidência entre as experiências relatadas é a importância da participação da família em todo o processo, o cuidado com a formação da identidade e do autoconceito positivo das crianças superdotadas, bem como a preocupação com a formação moral dessas crianças.

Um ponto a aprender com a experiência da Espanha é a maneira de olhar para a criança superdotada de maneira positiva acolhendo seus projetos, ideias e auxiliando-os no desenvolvimento de todo potencial criativo em diferentes habilidades. Há uma constante preocupação nesse contexto em promover o desafio aos superdotados.

Desta forma, esse estudo nos proporcionou entender que é necessário investir na formação para educadores e criar novas leis e diretrizes específicas ao atendimento educacional especializado dos superdotados, contatou também, a grande relevância dos NAAH/S e do ConBrasd para o Brasil, uma vez que os 


\section{Educere "Educare \\ REVISTA DE EdUCAC̈̃̃o}

Programa de Pós-Graduação em Educação - Universidade Estadual do Oeste do Paraná

estudos realizados a partir dessas experiências podem elevar qualitativamente a educação brasileira. 


\section{Educere Educare \\ RevisTA De EduCAC̄̃̃o}

Programa de Pós-Graduação em Educação - Universidade Estadual do Oeste do Paraná

\section{REFERÊNCIAS:}

ALMEIDA, L.S.; LOBO, C. C., ALMEIDA, A. I.S.; ROCHA, R. S.; PISKE, F. H. R. Processos cognitivos e de aprendizagem em crianças sobredotadas: atenção dos pais e professores. In: Piske [et. al] Processos afetivos e cognitivos de superdotados e talentosos. 1 ed. Curitiba: editora Prismas, 2017.

ALENCAR, E. M. L. S. de; FLEITH, D. S.; BRUNO-FARIA, M. de F. A medida da criatividade: possibilidades e desafios. In: ALENCAR, Eunice M. L. S. de; BRUNOFARIA, M. de F.; FLEITH, D. S. Medidas de criatividade: teoria e prática. Porto Alegre: Artmed, 2010. p. 11-34

BRASIL. Senado Federal. Lei de Diretrizes e Bases da Educação Nacional 9394/96. Brasília: $1996 . \quad$ Disponível em: <http://www.planalto.gov.br/ccivil_03/Leis/L9394.htm> Acesso em: 01 Nov. 2014.

BRASIL. Comissão de Constituição e Justiça e de Cidadania. Lei n. 8.035B/2010: Aprova o Plano Nacional de Educação. Disponível em: < file:///D:/Arquivos\%20Pessoais/Downloads/pne_redacao_final_ccjc\%20(1).pdf> Acesso em: 05 Nov. 2014.

COMES, G.; DÍAZ, E.; LUQUE, A.; MOLINER, O. La evaluación psicopedagógica del alumnado con altas capacidades intelectuales. In: Revista Educación Inclusiva, $\mathrm{n}$. 1, novembro, 2008. Disponivel em:< www.ujaen.es/revista/rei/linked/documentos/documentos/8.pdf $>$. Acesso em: 10 Jun. 2014.

DELOU, C, M. C. O Atendimento Educacional Especializado para alunos com Altas Habilidades/Superdotação no Ensino Superior: Possibilidades e desafios. In: MOREIRA, L. C.; STOLTZ, T. (Orgs). Altas Habilidades/Superdotação, Talento, Dotação e Educação. Curitiba: Juruá, 2012.

DELOU, C, M. C. Plano de atendimento educacional especializado integrado ao plano individual de ensino com vistas à aceleração de estudos: Sugestão adaptada do modelo de Joseph Renzulli. In: VIRGOLIM, A. M.R.; KONKIEWITZ, E. C. (ORGS.). Altas Habilidades/Superdotação, inteligência e criatividade: uma visão multidisciplinar. Campinas, SP: Papirus, 2014. 


\section{Educere Educare \\ ReVISTA DE EduCACÃ̃o}

Programa de Pós-Graduação em Educação - Universidade Estadual do Oeste do Paraná

ESPARZA, J.; FERRANDO, M.; SAINZ, M.; RUIZ, M. J., PIETRO, L. Avances em el estudio del talento científico. In: Piske [et. al] Processos afetivos e cognitivos de superdotados e talentosos. 1 ed. Curitiba: editora Prismas, 2017.

FERRANDO, M.; ROJO, A; FERRÁNDIZ, C. Intervención educativa en alumnado con altas capacidades intelectuales. Universidad de Murcia, 2007. Disponível em: $<\quad$ http://diversidad.murciaeduca.es/orientamur2/repositorio.php?rp=11> Acesso em: 10 Jun. 2014.

FREITAS, S. N.; PÉREZ, A. G. P. B. Altas habilidades/superdotação: atendimento especializado. 2. Ed. revista e ampliada. Marília: ABPEE, 2012.

GÁLVEZ, J. M.; GONZÁLEZ, M. T. G (Orgs). Alumnos precoces, superdotados y de altas capacidades. In: Ministerio de Educación y Cultura/Secretaría general de educación y formación profesional/Centro de Investigación y Documentación Educativa (CIDE), 2000. Disponivel em:<http://www.mecd.gob.es/dmsstatic/ac14aaff-b1db-4f09-9ac0-8d431b3d726d/publi-jorn-inclusiva-2004pdf.pdf >. Acesso em: 20 Jul. 2014.

MACHADO, J. M.; VESTENA, C.L.B. Cuestionario de indicativos de altas habilidades/superdotación de la ciudad de Guarapuava, Región Centro-Sur do Brazil. In: Anais I Congreso Internacional: Nuevas perspectivas em estúdio de la superdotación y el talento. Departamento de Psicologia Evolutiva y de Le educación. Universidad de Murcia, Espanha, 2016.

NICOLOSO, C.M.F.; FREITAS, S.N. A escola atual e o atendimento aos portadores de altas habilidades. In: Rev. Educ. Espec. Santa Maria, n.19, 2002. Disponivel em: http://coralx.ufsm.br/revce/ceesp/2002/01/a2.htm. Acesso em: 23 Nov 2014.

PEREIRA, V. L. P.; GUIMARÃES, T. G. Programas educacionais para alunos com altas habilidades. In: Fleith, D. de S.; Alencar, E. M. S. de (Orgs.). Desenvolvimento de Talentos e Altas Habilidades: Orientação a pais e professores. Porto Alegre: Artmed, 2007.

PÉREZ, Susana Graciela Pérez Barrera; FREITAS, Soraia Napoleão. Políticas públicas para as Altas Habilidades/Superdotação: incluir ainda é preciso. 


\section{Educere Educare \\ RevisTA De EduCAC̄̃̃o}

Programa de Pós-Graduação em Educação - Universidade Estadual do Oeste do Paraná

Revista Educação Especial, Santa Maria, p. 627-640, set. 2014. ISSN 1984-686X. Disponivel

<https://periodicos.ufsm.br/educacaoespecial/article/view/14274>. Acesso em: 05 abr. 2018. doi:http://dx.doi.org/10.5902/1984686X14274.

PISKE, F. H. R; MACHADO, J.M; BAHIA, S.; STOLTZ, T. (Orgs.). Altas Habilidades/ Superdotação (AH/SD): Criatividade e emoção. Curitiba: Editora Juruá, 2014.

PISKE, F.H.R.; VESTENA,C. L. B.; STOLTZ, T.; MACHADO,J.M.; BARBY, A. A. de, O.M.; BAHIA, S. FREITAS, S. P. Processos afetivos e cognitivos de superdotados e talentosos. Curitiba: Prismas, 2017.

PRIETO, M. D. S. Caracteristicas de la Experiencia del Aprendizaje Mediado: en Modificabilidad Cognitiva y P.E.I. Madrid España: Bruño, 1989.

RENZULLI, J. S.; REIS, S. M. The Schoolwide Enrichment Model: A how-to guide for educational excellence. 2 ed. Mansfield Center, CT: Creative Learning Press, 1997.

RENZULLI, J. S. O que é esta coisa chamada superdotação e como a desenvolvemos? Retrospectiva de vinte e cinco anos. In: Revista Educação, Porto Alegre, ano 27 n. 1, p. 75-134, jan./abr. 2004.

RIBEIRO, I.; VESTENA, C.L.B. Compreendendo a criança com Altas Habilidades/superdotação para poder atuar: experiências da Formação Continuada de Educadores Infantis em Guarapuava/PR. Dissertação de Mestrado (Impresso). Guarapuava: Universidade Estadual do Centro-Oeste, 2014.

SEIJO, R. C. T.; RUMAYOR, L.R.; SÁNCHEZ, N.M. Incidencia del aprendizaje cooperativo en los alumnos con altas capacidades: análisis cualitativo preliminar. In: 4th International Congress of Educational Sciences and Development. Disponivel em: http://congresoeducacion.es/edu_web4/LIBRO_ACTAS_2016.pdf >Acesso em: 09 Abr. 2018. 


\section{Educere Educare \\ RevisTA De EduCAC̄̃o}

Programa de Pós-Graduação em Educação - Universidade Estadual do Oeste do Paraná

SEIJO, R. C. T.; MARTÍNEZ, Y.; LÓPEZ, C.M.; LÓPEZ, M.L.P. Aprendizaje cooperativo y alumnos con altas capacidades: un programa de formación docente. In: 4th International Congress of Educational Sciences and Development. Disponivel em: http://congresoeducacion.es/edu_web4/LIBRO_ACTAS_2016.pdf $>$ Acesso em: 09 Abr. 2018.

STERNBERG, R.; GRIGORENKO, E.; FERRANDO, M.; HERNÁNDEZ, D.; FERRÁNDIZ, C.; BERMEJO, R. Enseñanza de la inteligencia exitosa para alumnos superdotados y talentos. In: REIFOP, 2000. Disponível em: <http://www.aufop.com> Acesso em: 15 Jun. 2014.

UNESCO. Declaração de Salamanca sobre principios, políticas e práticas na área das necessidades educativas especiais. Conferência Mundial de Educação Especial. Salamanca, Espanha. Disponivel em:< http://portal.mec.gov.br/seesp/arquivos/pdf/salamanca.pdf> Acesso em: 20 Nov. 2014.

Recebido em: 22/05/2015

Aprovado em: 02/10/207 